\title{
MARCAS DO GÊNERO NAS MIGRAÇÕES INTERNACIONAIS DAS MULHERES
}

\author{
Roberta de Alencar-Rodrigues \\ Universidade Autônoma de Barcelona, Barcelona, Espanha \\ Marlene Neves Strey \\ Pontifícia Universidade Católica do Rio Grande do Sul, Porto Alegre, Brasil \\ Leonor Cantera Espinosa \\ Universidade Autônoma de Barcelona, Barcelona, Espanha
}

RESUMO: O presente texto discute as questões de gênero e aculturação, considerando suas implicações nas migrações internacionais. Pretende-se compreender as transformações ocorridas nas relações de gênero decorrentes do processo migratório e, como consequência, a renegociação que membros de famílias imigrantes fazem no que concerne aos papéis de gênero. Considera-se que a aculturação promove o questionamento das relações de gênero, desestabilizando formas de ser homem e mulher cristalizadas na sociedade de origem. Nesse sentido, sublinha-se o fato de que a interface entre o conceito de aculturação e o de gênero é essencial para discutir as relações de gênero nas migrações internacionais contemporâneas, tornando visíveis as experiências de mulheres anteriormente negligenciadas.

PALAVRAS-CHAVE: relações de gênero; migrações internacionais; aculturação.

\section{GENDER MARK IN INTERNATIONAL MIGRATION OF IMMIGRANT WOMEN}

\begin{abstract}
The present text discusses gender issues and acculturation, considering their implications in international migrations. We intend to learn the transformations occurred in gender relations after migration and consequently the renegotiating process that family members do regarding gender roles. We consider that acculturation fosters questions toward gender relations, disordering the traditional roles women and men play in their societies of origin. Therefore, we highlight the fact that the interface between acculturation concept and gender is essential to discuss gender relations in international migrations, making women's experience visible where they were previously neglected.
\end{abstract}

KEYWORDS: gender relations; international migration; acculturation.

A história da humanidade é marcada pelos movimentos migratórios. Como as pesquisas históricas costumavam ser orientadas por valores tradicionais e patriarcais, a imigração foi abordada, quase sempre, como uma questão masculina, ocultando a presença feminina nesse contexto (Weinberg, 1992). A omissão da categoria gênero nos estudos migratórios reflete a história do domínio do sexo masculino sobre o feminino, que insistentemente prescreve a trajetória dos homens como sendo a norma (Vicente, 1999). Em virtude disso, a nossa proposta, neste texto, é realizar uma intersecção entre as questões de gênero e o processo migratório, procurando dar visibilidade às mulheres que, por muito tempo, foram ofuscadas. Para tanto, nos fundamentamos em Louro (1995, p. 106), ao reiterar que o gênero é "um elemento que pode provocar não só novas questões, mas novas respostas para velhas questões, além de colocar como ativos e visíveis sujeitos que usualmente têm estado escondidos nas análises mais tradicionais".
Apesar das mulheres não terem recebido a merecida atenção como sujeitos históricos que se inserem em processos migratórios, elas não se restringiam ao alçar seus voos. Leite (1997) realizou uma pesquisa documental com a literatura de viajantes estrangeiros que estiveram no Brasil durante o século XIX, mostrando uma série de dezesseis autoras desconhecidas. Os documentos que constituíram o material de análise daquela autora são os livros escritos pelas mulheres europeias que ingressaram num universo proibido, ao se afastarem da família e virem para o Brasil publicar suas transgressões nessas viagens. Entretanto, essas viajantes do século XIX precisaram, muitas vezes, assinar o nome do marido para terem seus textos publicados.

Já Donato (1992) expõe que, em 1930, as mulheres marcavam presença significativa entre os/as imigrantes para os Estados Unidos, sendo que em 1979 elas passam a somar mais de um milhão de todos/as os/ as imigrantes nesse país. Conforme essa autora, os Es- 
tados Unidos consistem no lugar de destino da maioria das mulheres imigrantes provenientes de vários países. Além dos Estados Unidos constituírem foco de atração de imigrantes, também é um país onde os estudos de gênero são mais consolidados, o que propulsiona pesquisas relativas ao cruzamento entre as relações de gênero e o fenômeno migratório (Bilac, 1995). Por isso, muito da literatura a ser apresentada, neste artigo, provém de estudos feitos com mulheres imigrantes na sociedade norte-americana.

$\mathrm{Na}$ década de 60, a influência do feminismo acadêmico leva à experiência das mulheres tornarem-se objeto de estudo (Bilac, 1995; Kosminky, 2004; Simon, 1992). Desse modo, as universidades passam a produzir conhecimento que envolve as mulheres em diferentes contextos, dentre eles os fenômenos migratórios (Simon, 1992). Além do movimento feminista, Kosminky (2004), citando Steven Gold, afirma que o aumento do número de mulheres imigrantes foi outro motivo para incorporar a categoria gênero nas pesquisas de migrações internacionais. Isto é, "a maior visibilidade numérica das mulheres contribuiu para questionar sua invisibilidade enquanto sujeito nos movimentos populacionais" (Assis \& Kosminsky, 2007, p. 695). Kosminky (2004) sublinha que a produção bibliográfica sobre gênero nas pesquisas migratórias nos Estados Unidos começou na década de 80 , e no Brasil, na década de 90 , o que nos conduz, neste trabalho, a apresentar investigações que datem principalmente esse período.

A invisibilidade das mulheres nas pesquisas sobre migrações internacionais não reside somente no seu ocultamento nesse fenômeno, mas também no retratá-las como coadjuvantes na posição de membro da família, conferindo um sentido estereotipado às suas experiências. Desse modo, investigações capturadas pelo discurso patriarcal deixam de dar voz às percepções das mulheres imigrantes em relação ao seu mundo, negligenciando o fato da imigração ser vivenciada de forma diferenciada por homens e mulheres (Kosminsky, 2004). Inicialmente, é a Antropologia feminista que busca compreender as repercussões da imigração na vida das mulheres, desvelando os diferentes efeitos produzidos na vida de ambos os sexos, que passam a questionar valores enraizados do que é ser mulher/homem e outros aspectos da cultura que carregam consigo (Brettel \& DeBerjeois, 1992).

Se a bagagem cultural que as mulheres imigrantes trazem consigo é colocada em suspeito, uma das razões se deve à sociedade hospedeira, que apresenta novas formas de ser homem e mulher. Nessa perspectiva, cabe aqui introduzirmos o conceito de aculturação, entendido como as mudanças ocorridas nos indivíduos após o contato intercultural (Berry, Poortinga, Segall \& Dasen, 2003), para mostrar que as concepções de gênero de mulheres e homens imigrantes são repensadas no processo migratório. Isso ocorre, segundo Dion e Dion (2001), porque as condições associadas à imigração e ao estabelecimento na sociedade hospedeira podem desafiar as expectativas em relação aos papéis de gênero. Com isso, passamos a definir primeiramente o conceito de gênero e, em seguida, nos propomos a realizar uma reflexão sobre as relações de gênero no contexto das migrações internacionais, buscando dar maior visibilidade às experiências das mulheres, que, por muito tempo, não tiveram suas experiências retratadas nos fluxos migratórios.

\section{Relações de gênero}

Trata-se de um desafio falar de um conceito tão complexo como o gênero, o qual pode ser definido sob diferentes ângulos. Neste artigo, não temos a pretensão de esboçar as diferentes formas como o termo gênero pode ser retratado, mas apresentar como ele tem sido descrito, de maneira geral, na literatura.

Há consenso entre as teóricas feministas quanto ao seu caráter relacional e ao repúdio ao determinismo biológico (Burin, 2004; Pereira, 2004; Scott, 1995; Strey, 2001). Adotando o gênero como categoria relacional, entendemos que mesmo priorizando, aqui, as experiências das mulheres imigrantes, tomamos como referência a sua relação com os homens. Desse modo, nos propomos a apresentar também os efeitos das migrações internacionais na vida dos homens. Além disso, Louro (1997) nos alerta para não abordarmos a característica relacional como se referindo à constituição de papéis masculinos e femininos, porque o termo papéis é reducionista. Como exemplo, Connel (1995) defende que, adotando o conceito de papel masculino, não nos permitimos ver as complexidades no interior da masculinidade e as múltiplas formas de masculinidade.

Concordamos com esses/as autores/as que essa terminologia é simplista, porém, ao nos remetermos à bibliografia, em língua inglesa, concernente às mulheres no contexto migratório, nos deparamos com o fato de que o conceito de gênero é abordado como "gender role" ou "sex-role", o que significa, em português, papel de gênero e papel sexual. Em função disso, foi necessário flexibilizar nosso entendimento do gênero consoante às ideias de Louro (1997), para podermos nos referir ao modo como o gênero é retratado em pesquisas que cruzam gênero e migração.

Depreende-se, a partir de Louro (1997), que refutar o determinismo biológico não significa não reconhecer que o gênero se constrói sobre os corpos sexuados. Esse conceito implica a construção social e histórica produzida sobre as características biológicas. Isso é, "definições de homem e mulher, do masculino 
e do feminino são efetivamente construções históricas e não simples reflexo de um fato biológico" (Louro, 1995, p. 118). Nesse caso, devemos ter cuidado com os estereótipos que, segundo Bertolote (1994, p. 116), atuam com a força da lei, em que o "ser feminino tem englobado o ser 'fêmea' (biológico)".

Sendo assim, entendemos o gênero como produto fabricado da cultura, e não como atributo estável e inato (Pyke \& Johnson, 2003). Por ser um construto dinâmico que varia entre os grupos étnicos, os conceitos de feminilidade e masculinidade podem assumir diferentes significados ao longo de diversos grupos culturais (Dion \& Dion, 2001; Gowan \& Trevi, 1998), bem como pode se distinguir dentro de um mesmo grupo étnico. Embora as relações de gênero sofram modificações num mesmo cenário cultural, consideramos que as migrações podem atuar como um motor que impulsiona e desafia mudanças de crenças culturais e atitudes relativas ao gênero.

$\mathrm{O}$ objeto de gênero sofreu deslocamentos, pois passou do objeto empírico mulheres para objeto teórico gênero (Pereira, 2004; Strey, 2001). Embora, num primeiro momento, tenham enfocado somente as mulheres, isso foi indispensável para "tornar visível sujeitos até então excluídos da história" (Louro, 1995, p. 126). Investigar as relações de gênero permite incluir sujeitos como homens, gays, lésbicas e transexuais nesse campo de investigação, problematizando aqueles que eram objetos centrais de estudo e percebendo melhor os excluídos.

Scott (1995, p. 86) afirma que o gênero "é um elemento constitutivo das relações sociais baseadas nas diferenças percebidas entre os sexos e o gênero é uma forma primária de dar significado às relações de poder". A partir dessa afirmação, Louro (1995, p. 106) nos explica que o gênero se configura num primeiro espaço de domínio, no interior do qual o poder é articulado. Com o auxílio dessa autora, podemos entender que "ser do gênero feminino ou do gênero masculino leva a perceber o mundo diferentemente, a estar no mundo de modos diferentes. Em tudo isso, há diferença quanto à distribuição de poder". Nessa perspectiva, a nossa tarefa reside, neste artigo, em conferir brilho às mulheres imigrantes que foram tratadas historicamente como inferiores, reprimidas por estruturas de poder (Butler, 2003). Tendo como alerta que mulheres imigrantes cruzam arenas conflitantes em relação às expectativas de gênero, também estamos interessadas em desvelar as diferentes performances empreendidas por elas, dependendo do contexto cultural em que se inserem (Pyke \& Johnson, 2003).

Tendo em vista que o processo migratório gera identidades plurais e identidades contestadas (Woodward, 2001), consideramos que o gênero, como fator constituinte da identidade do sujeito (Louro, 1997), é um aspecto questionado na experiência migratória. Sendo assim, mulheres e homens imigrantes têm suas "identidades abandonadas, segundo as propostas em curso" (Butler, 2003, p.37), pois suas identidades são constantemente construídas através da sua interação com o ambiente sociocultural (Lewin, 2001). Rejeitamos visões simplórias acerca da identidade como algo fixo, essencial e permanente e insistimos com Hall (2000, p.13), quando destaca que a identidade é "formada e transformada continuamente em relação às formas pelas quais somos representados ou interpelados nos sistemas culturais que nos rodeiam". O gênero, bem como a identidade são, portanto, definidos historicamente, e não biologicamente.

\section{As relações de gênero nas migrações internacionais}

Pesquisas no âmbito das migrações internacionais através das lentes do gênero nos possibilitam conhecer os desafios que os/as imigrantes enfrentam em suas famílias para renegociar expectativas em relação ao comportamento de gênero de cada membro (Dion \& Dion, 2001). A maneira pela qual esse embate cultural é vivido relaciona-se com o processo de adaptação cultural e pessoal.

Estudos de imigração têm enfocado as formas de participação da mulher no mercado de trabalho, a relação entre o trabalho doméstico e o trabalho remunerado, a vida familiar, as alterações nas relações de gênero, as diferenças de status da mulher no país de origem e no país hospedeiro (Bilac, 1995; Dion \& Dion, 2001). Posto isso, passamos a apresentar algumas pesquisas, nas quais as questões de gênero são priorizadas, reforçando a importância de aliar essa categoria de análise às pesquisas (Louro, 1995).

O ponto de partida para nossa reflexão acerca das repercussões do fenômeno migratório na vida de homens e mulheres é através do estudo de Kosminsky (2004) com algumas famílias judias que migraram para Nova York e São Paulo na década de 20. Essa autora discute como as relações de gênero podem ser vividas de formas diferentes pelas mulheres judias nas cidades de São Paulo e Nova Iorque. Para tanto, ela investigou as filhas das imigrantes judias, buscando examinar os padrões de atitudes relacionados ao gênero expresso nas entrevistas.

Em Nova Iorque, as imigrantes judias se depararam com uma sociedade que oferecia oportunidades para homens e mulheres. Desse modo, muitos judeus trabalharam na indústria norte-americana na década de 20. Mesmo assim, havia discriminação contra as mulheres, pois elas escutavam piadas e palavrões dos patrões 
no ambiente das fábricas. Naquele contexto, o saldo da imigração para as mulheres judias em Nova Iorque foi a possibilidade de conquistar certa independência econômica, poder frequentar teatros, cursos de inglês e participar do movimento feminista.

No entanto, o débito da imigração para as mulheres judias em Nova Iorque foi a perda do suporte da família, uma vez que muitos maridos abandonaram o lar. Kosminsky (2004) levanta como hipótese o fato de que os homens na Europa Oriental mantinham relação de parceria com suas esposas, e, nos Estados Unidos, a cultura ocidental da década de 20 esperava que ele fosse o provedor. Em solo americano, as tensões vividas pelas mulheres imigrantes judias e pelas suas filhas nascidas em Nova Iorque estão relacionadas, por um lado, às experiências de independência advindas do trabalho e da participação política e, por outro lado, à pressão em desempenhar o papel de esposa e dona de casa. Em função disso, a importância da família como valor trazido pelos/as imigrantes foi desestabilizada. Por sua vez, as mulheres imigrantes judias conquistaram, nessa sociedade, autonomia nas relações de gênero no trabalho, em casa e na rua, podendo ter mais flexibilidade na escolha de seus parceiros.

No cenário brasileiro na década de 20 , as mulheres imigrantes judias encontraram uma sociedade conservadora que questionava as mulheres que saíam sozinhas nas ruas para trabalhar. Em São Paulo, o emprego feminino não era bem visto, reforçando a postura das famílias judias em rejeitar o trabalho feminino antes do casamento. O valor do casamento, característico da cultura judaica, encontrou ambiente propício para se perpetuar na sociedade brasileira patriarcal.

Diante desse quadro de imigração judaica, podemos depreender que a situação enfrentada pelas mulheres imigrantes e suas filhas ocorreu de forma diferente em Nova Iorque e em São Paulo, considerando os aspectos de trabalho, família e participação política. Entretanto, Kosminsky (2004) descreve como semelhança entre as cidades o fato das mulheres da segunda geração terem tido acesso ao ensino superior, apesar de que em nenhum lugar seguiram cursos que promovessem carreiras de prestígio.

Outras pesquisas envolvendo migrações internacionais apontam que esse deslocamento físico pode gerar sintomas psicossomáticos nos membros familiares, uma vez que a mudança geográfica é acompanhada de transformações culturais. Pesquisas, a partir de experiências clínicas com mulheres latinas nos Estados Unidos, revelam que os/as profissionais da saúde devem ter o cuidado de considerar os fatores inerentes ao processo migratório, como aculturação, conflitos nos papéis de gênero no atendimento de mulheres imigrantes (Espin, 1987; Soto \& Shaver, 1982). Segundo esses/as autores/ as, não entender essas questões inerentes ao processo migratório pode conduzir a um diagnóstico errado.

Espin (1987) investigou mulheres latinas em processo psicoterapêutico nos Estados Unidos, verificando que o aumento da empregabilidade feminina e a perda do status e da autoridade do homem geraram tensão na família. Nessa pesquisa qualitativa, a autora constatou que as mulheres que migraram sozinhas se depararam com solidão, vergonha e culpa, porém se sentiram mais livres do controle da família para buscar novos padrões de comportamento do que aquelas que migraram acompanhadas da família.

Como ilustração da autoridade masculina abalada no processo migratório, Lim (1997) conduziu seu estudo com casais imigrantes coreanos nos Estados Unidos, em que os homens se queixavam que suas mulheres passaram a desenvolver atitudes assertivas quando começaram a trabalhar, dizendo o que queriam. Além disso, a assertividade contribuiu para que pedissem envolvimento dos esposos nas tarefas domésticas. Entretanto, os maridos dessas mulheres que trabalhavam reportaram que a responsabilidade principal de suas mulheres ainda são as tarefas relacionadas às famílias, percebendo o trabalho de suas esposas como opção.

Estudo semelhante ao de Espin (1987) foi conduzido por Soto e Shaver (1982), a partir do trabalho clínico com mulheres porto-riquenhas também nos Estados Unidos. Esses/as autores/as pontuam que a cultura porto-riquenha é uma mescla da cultura espanhola e catolicismo, prescrevendo a superioridade e autoridade masculinas e a inferioridade e submissão femininas. $\mathrm{O}$ atendimento clínico de algumas mulheres porto-riquenhas mostrou que elas colocam em suspeito os valores da cultura porto-riquenha. Esse questionamento pode gerar conflitos, manifestando-se através de sintomas psicossomáticos e de depressão.

Diante desses estudos, não podemos depreender que as mulheres são mais vulneráveis à depressão na condição de imigrante, pois Lewin (2001) pesquisou imigrantes iranianos/as e observou que eles também adoeceram frente às exigências de mudanças culturais. Nesse caso, é possível considerar que a situação migratória convidou essas mulheres a desempenharem novos papéis, e que, para isso acontecer, foi necessário desacomodar velhos hábitos sob clima de tensão, ansiedade e até de depressão.

Desse modo, Soto e Shaver (1982) pesquisaram os aspectos da saúde e do bem-estar das mulheres imigrantes porto-riquenhas, avaliando o modo pelo qual elas expressavam atitudes e experiências em relação aos papéis femininos. Para tanto, aplicaram alguns instrumentos em 278 mulheres, com idade de 18 a 55 anos, recrutadas em comunidades porto-riquenhas na área metropolitana de Nova Iorque. Essa amostra consistiu 
de mulheres da primeira geração nascida em Porto Rico e da segunda geração concebida nos Estados Unidos de uma mãe que nasceu em Porto Rico.

Os resultados dessa pesquisa sinalizam que as variáveis geração e educação afetam significativamente o papel sexual tradicional, pois as participantes da segunda geração, com maior nível educacional, mostraram-se menos tradicionais nos papéis sexuais e com menos sintomas. Isto é, a segunda geração de mulheres porto-riquenhas nascidas nos Estados Unidos evidencia mais formação educacional e menos papéis sexuais tradicionais quando comparadas à primeira geração, o que sinaliza que a educação foi um dos fatores de empoderamento dessas mulheres. Nesse sentido, é importante ressaltar, como vimos anteriormente, que a oportunidade de emprego e a presença de relações de gênero igualitárias da sociedade receptora configuram outros fatores que contribuem ao empoderamento feminino de mulheres imigrantes.

Os papéis sexuais tradicionais foram associados à baixa assertividade. Do mesmo modo, as mulheres envolvidas com religião apresentaram-se mais tradicionais nos papéis sexuais e menos assertivas do que aquelas nãoreligiosas. Esses achados trazem à baila a importância da educação no processo de adaptação, pois viabilizam ferramentas linguísticas e conceituais que capacitam as mulheres a enfrentarem um novo ambiente cultural. Nesse sentido, as escolas e as instituições de ensino devem despertar para o seu papel no processo de aculturação, uma vez que o estudo de Soto e Shaver (1982) evidenciou que a educação é um fator preditivo do decréscimo de tradicionalismo, aumento de assertividade e saúde mental. Se as mulheres mais religiosas demonstraram atitudes mais tradicionais, podemos inferir que a ideologia perpassada nas igrejas prescreve a desigualdade entre homens e mulheres, ensinando que as mulheres devem seguir o modelo de Virgem Maria, sendo boa mãe e boa esposa (Baldwin \& DeSouza, 2001).

Já na pesquisa de Kranau, Green e ValenciaWeber (1982), o nível educacional denotou o grau de aculturação, pois as mulheres imigrantes hispânicas mais educadas apresentaram maior probabilidade de se aculturarem na sociedade americana e, portanto, expressarem atitudes mais liberais. Esses/as autores/as aplicaram alguns instrumentos em 60 hispânicas, contatadas através de universidades estaduais de Oklahoma, Estados Unidos, objetivando medir a aculturação e os efeitos das mudanças de comportamento das mulheres. Como achados, verificaram que o status conjugal e a idade estão correlacionados negativamente com aculturação, sugerindo que é mais provável que as mulheres hispânicas mais aculturadas sejam solteiras e jovens.

Valentine e Mosley (2000) compararam grupos da primeira e segunda geração de mexicanos com os americanos, constatando que as mudanças relativas aos papéis sexuais decorrem do aumento do número de oportunidades de emprego e estudo oferecidas aos mexicano-americanos nos Estados Unidos. Gowan e Trevi (1998) estudaram as atitudes de 76 mulheres mexicano-americanas e 62 homens mexicano-americanos em relação aos papéis femininos no mercado de trabalho e no cuidado com as crianças. Os resultados dessa investigação indicam que os homens mexicanoamericanos expressaram uma visão mais tradicional relativa ao papel de mulheres e homens na família e na carreira do que as mulheres mexicano-americanas.

Isso pode repercutir no ambiente doméstico, na medida em que o mexicano-americano pode ter crenças de gênero tradicionais, as quais dificultam a inserção da mulher no mercado de trabalho, especialmente se tiver filhos. Além disso, trabalhar fora de casa diminui a dependência da mulher do homem, bem como a quantidade de tempo que ela despende para atender as necessidades dele.

Cabe lembrar que atualmente os homens estão mais envolvidos com questões familiares, porém é mais provável que as mulheres experimentem mais estresse nessa jornada dupla no trabalho e em casa (Dion \& Dion, 2001; Gowan \& Trevi, 1998). Mesmo que hoje as mulheres estejam investindo mais na carreira, elas carregam mais responsabilidades no que concerne à manutenção do lar e ao cuidado dos filhos, o que desvenda uma das desigualdades mais evidentes em nível cotidiano (Vicente, 1999).

Além dos conflitos gerados no ambiente familiar, Gowan e Trevi (1998) verificaram que as mulheres podem vivenciar certa tensão no trabalho, caso o empregador seja mexicano-americano. Novamente a discriminação contra a mulher se inscreve quando o mexicano-americano, por não considerar a mulher pertencente ao mercado de trabalho, acaba não oferecendo as mesmas oportunidades para homens e mulheres.

Ao nos debruçarmos sobre os dados obtidos na pesquisa de Gowan e Trevi (1998), poderíamos levantar como hipótese que os homens americanos revelariam atitudes mais igualitárias relacionadas ao trabalho feminino. Entretanto, Acuña e Bruner (2001), ao compararem os estereótipos de masculinidade e feminilidade entre estudantes universitários do México e Estados Unidos, verificaram que não existiram diferenças significativas em relação ao grau que homens americanos e mexicanos se atribuem características estereotipadas masculinas. Tal apontamento nos conduz a pensar que os homens americanos também podem manifestar preconceito em relação ao emprego feminino.

Na verdade, a pesquisa de Pyke e Johnson (2003) com a segunda geração de imigrantes coreanas e vietnamitas na Califórinia, Estados Unidos, ilustra que os 
homens americanos podem tratar diferente as mulheres trabalhadoras, se elas forem imigrantes. Essas autoras explicam que o homem americano, ao preconceber que as mulheres asiáticas são subservientes, acabam se dirigindo às imigrantes de modo divergente ao tratamento dado às mulheres americanas. As asiáticas entrevistadas por Pyke e Johnson (2003) reportaram que empreendem esforços extras para não confirmar essas suposições acerca da submissão feminina asiática. $\mathrm{O}$ fato de essas asiáticas negociarem suas identidades em alguns contextos, mostrando-se mais falantes e sociáveis em oposição aos estereótipos raciais, desvela uma forma de construir o gênero forçado e inventado. Em outras palavras, elas negociam categorias raciais, a fim de usar identidades que as empoderam.

Isso se configura um jogo de identidades, no qual as participantes da pesquisa de Pyke e Johnson (2003) afirmam mudar sua personalidade como "camaleões", dependendo do domínio cultural no qual se inserem. Como exemplo, as autoras descrevem o depoimento de uma das respondentes que afirma se comportar, dentro do grupo de asiáticas, conforme as expectativas da cultura asiática, isso é, mostrando-se reservada e passiva, enquanto se sente mais livre e espontânea diante de membros da cultura americana. De modo geral, a análise das entrevistas realizadas por Pyke e Johnson (2003) sugere que elas não se sentem quem elas realmente são no seu lugar étnico, porém experenciam seu self autêntico na cultura americana. Em virtude disso, não aceitam a feminilidade asiática e glorificam a feminilidade americana.

Essa percepção de que o desenvolvimento do gênero no mundo asiático é opressivo leva a segunda geração de imigrantes asiáticas a rejeitar a cultura étnica, escolhendo o modo americano de fazer o gênero. Abraçando o mundo branco para ganhar poder, essas asiáticas estão reforçando o racismo antiasiático e a superioridade branca (Pyke \& Johnson, 2003). Mesmo que a inserção na cultura americana se constitua uma prática libertadora para as mulheres asiáticas, uma vez que experimentaram uma nova possibilidade de ser mulher, percebemos que simplesmente creditar vantagens ao modo americano de fazer o gênero também se configura um aprisionamento para essas mulheres, pois ficam num beco sem saída entre preservar valores asiáticos ou assimilar a cultura americana. Essas duas possibilidades de construírem sua feminilidade parecem restringir outras múltiplas formas de ser mulher, o que, de algum modo, engessa o modo como essas mulheres asiáticas se constituem como sujeitos.

Da mesma forma que Gowan e Trevi (1998) identificaram conflitos nas famílias mexicano-americanas advindos do processo de aculturação, Pyke e Johnson (2003) constataram que as vietnamitas e coreanas experenciam tensão relativa às questões de gênero na dinâmica familiar, pois elas adquirem maior poder decisório e autonomia ao passo que seus maridos perdem o poder econômico e aumentam a dependência delas. Essa perda ou diminuição da autoridade do homem perpassa também as famílias açorianas analisadas por Feldman-Bianco e Huse (1995) nos Estados Unidos. Elas examinaram o modo como duas gerações de mulheres portuguesas constroem e reconstroem as suas memórias da terra natal no contexto de imigração em Massachussetts, Estados Unidos, observando que a imigração significa empoderamento nas relações conjugais decorrente da distribuição igualitária dos afazeres domésticos e da conquista da independência econômica. Nesse cenário, as autoras atestam que as mulheres que migraram mais jovens costumam questionar os valores culturais e reconstruir as relações de gênero, inclinando-se, geralmente, pela identidade americana por considerarem a constituição do gênero feminino nos Açores como estático.

A inserção numa nova cultura pode gerar efeitos na relação conjugal, conforme constatado na tese de doutorado de DeBiaggi (2003). Essa autora pesquisou 50 famílias brasileiras em Boston, Estados Unidos, que apresentaram mudanças nas relações de gênero após a inserção feminina no mercado de trabalho. Assim, o emprego remunerado gerou não somente poder econômico, mas aumento da autoestima e autoconfiança. Por sua vez, os homens imigrantes brasileiros sentiram rebaixamento do seu status, porém passaram a dividir as tarefas domésticas, a participar do cuidado dos filhos, mostrando-se também mais expressivos no relacionamento conjugal.

Este rearranjo familiar também foi verificado por Assis (2007) na sua investigação com brasileiros/as em Boston, Estados Unidos, pois, segundo a pesquisadora, os casais vivenciam outro padrão de relações de gênero quando chegam aos Estados Unidos, já que, na sociedade receptora, as relações são menos hierárquicas e há maior divisão de tarefas domésticas. Nesse estudo, a autora constatou que a redefinição das relações de gênero foi favorecida pela vivência de empoderamento e maior autonomia devido aos ganhos adquiridos através do trabalho. Por outro lado, os homens brasileiros precisam dividir a autoridade, ao mesmo tempo em que são confrontados com as expectativas de relações mais igualitárias.

Tal como DeBiaggi (2003) e Assis (2007), Sousa (2007) também pesquisou o coletivo brasileiro, assinalando os ganhos percebidos pelas mulheres brasileiras decorrentes da emigração para Itália: emprego, maior salário e poder aquisitivo e decisório, amizades novas. Todas essas conquistas psicológicas, sociais e culturais configuram o saldo positivo do processo migratório das 
mulheres brasileiras imigrantes na Itália. No entanto, muitas reportaram problema para integração social como sentimento de solidão, medo de perder a guarda dos filhos se voltam para o Brasil, interferência da sogra. A crença nos benefícios concretos (sistema de saúde e educacional) oferecidos pela sociedade italiana é a maneira encontrada para ter forças para superar esses problemas.

As mulheres imigrantes iranianas melhoraram sua posição na família, quando passaram a trabalhar na Suécia. No Irã, elas encontravam-se excluídas de certas áreas do mercado de trabalho e, na Suécia, percebem que seu trabalho é considerado valioso (Lewin, 2001). Os homens imigrantes iranianos apresentam dificuldades em completar a sua educação na Suécia e em obter trabalho apropriado, pois se recusam a aceitar trabalhos abaixo de suas habilidades. Por outro lado, as mulheres iranianas têm aceitado empregos menos qualificados e continuam a sua educação em diferentes níveis. Essa alternância de status respinga nas relações conjugais, conforme dados que apontam o número de divórcios entre iranianos ser maior do que entre suecos e muitos outros grupos de imigrantes na Suécia em 1995 (Lewin, 2001). Nesse caso, podemos verificar que as desigualdades persistem, pois elas não têm a opção de escolher seus trabalhos, porém o simples fato de não dependerem mais economicamente dos seus maridos gera satisfação nelas. É importante salientar que não é somente o emprego que proporciona relações mais igualitárias às mulheres, mas o fato da inserção na cultura sueca favorecer que os direitos dessas mulheres sejam efetivados.

Lewin (2001) assinala que as mulheres iranianas têm sido mais bem-sucedidas em se adaptar na sociedade sueca devido à sua ocupação profissional e aos direitos garantidos pela legislação sueca. Isso gera uma atitude positiva em relação à sociedade, aumentando o seu desejo por integração. Mesmo que, na Suécia, as mulheres não sejam consideradas tão iguais aos homens, o que importa para as mulheres imigrantes iranianas é o fato de terem adquirido mudança de seu status na família e no trabalho. Em contrapartida, os homens imigrantes iranianos não encontram, na Suécia, um trabalho que corresponda à sua educação, o que abala sua autoimagem de figura dominante dentro da família e do círculo social. Com efeito, eles expressam uma atitude negativa em direção à sociedade sueca, não interagindo com a nova sociedade e desenvolvendo sintomas de depressão e suicídio. Nessa situação, Lewin (2001) interpreta que os iranianos encontram-se numa posição de serem considerados o outro na sociedade sueca, enquanto as iranianas ganham a possibilidade de superar a falta de poder pelo menos na estrutura da sua família.

Essa integração bem-sucedida na sociedade sueca verificada por Lewin (2001) também foi assinalada por Cavalcanti (2006) no seu estudo com mulheres brasileiras na Espanha. Segundo esse autor, algumas brasileiras residentes em Barcelona e Madri optam pela atividade empresarial como estratégia de mobilidade social e como forma de escapar aos setores de empregos tradicionais destinados às mulheres imigrantes: limpeza, cuidado de crianças e idosos, serviço de garçonetes em restaurantes ou a prostituição. Portanto, investir no setor empresarial lhes permite obter uma maior autonomia laboral e melhor status social. Além disso, esse protagonismo empreendido por mulheres imigrantes empresárias impulsiona rever a construção social do imigrante como categoria social. Com isso, Cavalcanti quer dizer que essas iniciativas emprendedoras das mulheres imigrantes brasileiras residentes em Barcelona e Madri constituem elementos importantes para problematizar e desconstruir a representação do/a "imigrante" como categoria social baseada em imagens de pobreza e marginalidade. Do mesmo modo, o exercício de atividades comerciais e empreendedoras por essas mulheres imigrantes contribui com a desconstrução da noção de imigrante como força de trabalho que vem à Espanha roubar emprego dos nacionais. Isso é, seus estabelecimentos comerciais favorecem a economia local ao gerar empregos, enfraquecendo a concepção de imigrante como apenas mão-de-obra no país de recepção.

Por outro lado, outras investigações sobre correntes migratórios de brasileiros para os Estados Unidos (Fleischer, 2002; Martes, 1998) evidenciam o mercado de trabalho segregado por gênero devido à tendência de as mulheres imigrantes brasileiras trabalharem com o serviço doméstico, enquanto os homens imigrantes brasileiros se ocupam da construção civil.

A manutenção da identidade étnica em famílias indianas nos Estados Unidos foi tornando-se uma tarefa complexa devido à emergência de novas questões como namoro, casamento, obediência aos desejos dos pais. Diante desse contexto, Dasgupta (1998) se propôs a estudar 46 famílias imigrantes indianas de classe média, objetivando examinar indicadores da transmissão da cultura como atitudes em relação à mulher e ao namoro entre imigrantes indianos/as e seus filhos/as. Nessa pesquisa, a autora averiguou que muitas mulheres da segunda geração se queixam sobre as prescrições rígidas de gênero que lhes são impostas, pois elas são mais monitoradas que seus irmãos. E coube às mães o papel de manutenção da cultura asiática, as quais são pressionadas a transmitir os papéis tradicionais de gênero, quando suas filhas tornam-se adolescentes. Em contrapartida, o grupo de pais e mães que expressou atitudes igualitárias de gênero manifestou altos graus de ansiedade. Dion e Dion (2001) confirmam que, em famílias imigrantes, o monitoramento do comportamento das filhas é maior 
do que o dos filhos, quando os valores familiares da sociedade de origem são díspares dos encontrados na sociedade receptora.

Nas famílias imigrantes, os pais esperam que as filhas tenham oportunidades educacionais e de carreira na sociedade receptora, apesar de almejarem que elas se comportem conforme os valores da sociedade de origem (Dion \& Dion, 2001). Essa expectativa dos pais de que as filhas mantenham a herança cultural da sociedade de origem, apesar de ser fonte de discórdia, é motivo de orgulho. As filhas de famílias imigrantes, por sua vez, apresentam menos visões tradicionais relativas às questões de gênero do que seus pares. Novamente percebemos que a migração não imuniza as desigualdades, pois embora as mulheres possam ter possibilidade de trabalhar e estudar, elas continuam recebendo tratamento diferenciado.

As mulheres imigrantes parecem ser pressionadas a preservar os valores do seu país de origem, pois Assis (2004) identificou que as mulheres imigrantes brasileiras nos Estados Unidos assumiam o papel de mantenedoras das redes sociais do país de origem, enquanto Dion e Dion (2001) constataram, através de estudo multiétnico com universitários/as, que as mulheres de famílias imigrantes nascidas no Canadá indicaram forte desejo em entender o significado da etnicidade das suas vidas, quando comparadas aos homens. Embora elas reportem maior envolvimento na participação etnocultural do que os homens, ambos/as não diferem no grau em que apresentam sentimento de pertencimento à bagagem etnocultural. Até agora pudemos identificar que os pontos de contato entre os estudos apresentados anteriormente sinalizam que "fazer-se homem ou mulher nem sempre supõe o mesmo em diferentes sociedades ou em diferentes épocas" (Strey, 2001, p. 49). Identificamos que as mulheres imigrantes, descritas ao longo deste artigo através de pesquisas, adquiriram mais espaço no âmbito profissional e doméstico, porém ainda são conquistas tímidas perpassadas por desigualdades, uma vez que podem ser tratadas diferentemente de seus irmãos na família, e não podem escolher o seu trabalho na sociedade acolhedora.

\section{Considerações finais}

Sabemos que a temática das relações de gênero nas migrações internacionais não se esgota aqui no desfecho deste artigo, mas conseguimos realizar a nossa proposta em empreender uma reflexão sobre as mudanças nas relações entre homens e mulheres no fenômeno migratório. Assim, destacamos a necessidade de propiciar maior visibilidade às experiências das mulheres, por muito tempo negligenciadas nos estudos sobre migração.
Ao fazer este estudo, partimos de um caminho interdisciplinar através dos estudos de gênero, do conceito de aculturação, enfocando que o contexto de migração incita mudanças de atitudes e valores. Percebemos que mulheres mais aculturadas, após a imigração, modificam sua posição em relação ao homem. Esse trânsito nas pesquisas migratórias nos possibilitou constatar que o gênero não é apenas uma identidade ou papéis aprendidos na infância, mas sim um sistema em constante movimento afetado pelo contexto cultural.

Diante do exposto, podemos afirmar que algumas mulheres imigrantes vislumbraram mais autonomia nas suas ações ao ingressar no mercado de trabalho, conquistar poder econômico e, assim, exigir de seus maridos participação nas atividades domésticas e cuidado dos filhos. No entanto, isso tende a acontecer quando as mulheres se deslocam de uma sociedade mais patriarcal para uma sociedade mais liberal, pois, se elas se inserirem num país onde a cultura também é tradicional, é possível que os valores sejam reforçados. Nessa direção, salientamos a construção das relações de gênero influenciada pelo contexto cultural, sem indícios de determinação biológica.

Entretanto, a emancipação das mulheres imigrantes pode ser permeada por relações de desigualdade com base na diferença, na medida em que cabe a elas transmitir a cultura de origem para sua prole e ainda monitorar o comportamento das filhas. Ainda esse tratamento diferenciado dado a homens e mulheres está presente na crença de que o trabalho feminino é secundário, como meio de ajudar o marido nas despesas domésticas. Enquanto houver mulheres e homens considerando as atividades femininas como segundo plano, elas não se constituirão como sujeitos da sua história e protagonistas de sua vida, mas sim coadjuvantes guiadas pela dominação masculina.

Essa desigualdade baseada na diferença também caracteriza o mercado de trabalho que as mulheres imigrantes encontram na sociedade receptora, pois, geralmente, exercem atividades tradicionalmente femininas, como o serviço doméstico. Apesar de desempenharem trabalhos de baixo status social, consideram que o movimento migratório configura uma estratégia de busca de autonomia e oportunidade para escapar de poucas oportunidades em seus países de origem. Assim, oportunidades de emprego e legislação favorável no que diz respeito às discriminações de gênero da sociedade de acolhida constituem benefícios na hora de emigrar.

Prosseguindo com nossas considerações, reiteramos a inclusão do gênero nas pesquisas migratórias como forma de propor novas formulações às velhas questões. Assim, tomamos conhecimento das peculiaridades das experiências das mulheres imigrantes em uma nova cultura, na qual elas assumem também o foco 
principal. Direcionar os holofotes para as mulheres imigrantes é permitir que elas sejam retratadas na sua própria trajetória de deslocamento, e não como mulheres que acompanham os filhos e maridos no fenômeno migratório. Portanto, este artigo ilustra que a inclusão do gênero contribui na análise do fenômeno migratório, reforçando os estudos feministas que desde a metade da década de setenta já questionam a imagem estereotipada de mulheres imigrantes como dependentes passivas.

Os conceitos de aculturação e das relações de gênero demonstram serem saberes complementares indispensáveis ao entendimento das migrações internacionais, na medida em que navegar em mares culturais diferentes implica se aculturar e, assim, descristalizar padrões de gênero rígidos. No entanto, percebemos que a mera assimilação da cultura local pelas mulheres imigrantes não é a melhor saída para o impasse das desigualdades nas relações de gênero, pois, negando a cultura de origem e absorvendo automaticamente a cultura hospedeira, acabam não imprimindo o seu modo de ser na maneira de fazer o gênero.

Esses aportes teóricos precisam ser interligados e, como tal, precisam ser considerados não somente em pesquisas sobre migrações internacionais, como em serviços de assistência que venham a acolher a população imigrante. Como vimos, profissionais embebidos de noções de gênero e aculturação podem estar mais capacitados para intervir junto à comunidade imigrante, sem incorrer no risco de medicalizar e diagnosticar conflitos culturais.

\section{Referências bibliográficas}

Acuña, L. \& Bruner, C. (2001). Estereótipos de masculinidad y femininidad en México y en Estados Unidos. Revista Interamericana de Psicologia, 35(1), 31-51.

Assis, G. (2004). "De Criciúma para Boston": tecendo redes familiares na migração internacional. In S. DeBiaggi \& G. Paiva (Orgs.), Psicologia, E/Imigração e Cultura (pp. 111-134). São Paulo: Casa do Psicólogo.

Assis, G. (2007). Mulheres migrantes no passado e no presente: gênero, redes sociais e migração internacional. Estudos $\mathrm{Fe}$ ministas, 15(3), 745-772.

Assis, G. \& Kosminsky, E. (2007). Gênero e migrações contemporâneas. Estudos Feministas, 15(3), 695-697.

Baldwin, J. \& DeSouza, E. (2001). Modelo de María and machismo: The social construction of gender in Brazil. Revista Interamericana de Psicologia, 35(1), 9-29.

Berry, J., Poortinga, Y., Segall, M., \& Dasen, P. (2003). Crosscultural psychology: Research and applications. New York: Cambridge University Press.

Bertolote, S. (1994). Estereótipos, educação e saúde mental da mulher. Educação \& Realidade, 19(2), 115-133.

Bilac, E. (1995). Gênero, família e migrações internacionais. In N. Patarra (Coord), Emigração e imigrações internacionais no Brasil contemporâneo (pp. 65-77). São Paulo: Funap.
Brettell, C. \& DeBerjeois, P. (1992). Anthropology and the study of immigrant women. In D. Gabaccia (Ed.), Seeking common ground: Multidisciplinary studies of immigrant women in the United States (pp.41-65). Westport, CT: Praeger.

Burin, M. (2004). Prefácio. In M. Strey, S. Cabeda, \& D. Prehn (Orgs.), Gênero e cultura: questões contemporâneas (pp. 9-12). Porto Alegre: Edipucrs.

Butler, J. (2003). Problemas de gênero: feminismo e subversão da identidade. Rio de Janeiro: Civilização Brasileira.

Cavalcanti, L. (2006, agosto). O protagonismo empresarial imigrante a partir de uma perspectiva de gênero: o caso das brasileiras nas cidades de Madri e Barcelona. In Anais Seminário Internacional Fazendo Gênero, 7 (pp. 1-7). Florianópolis: Editora Mulheres.

Connel, R. (1995). Políticas da masculinidade. Educação \& Realidade, 20(2), 185-206.

Dasgupta, S. (1998). Gender roles and cultural continuity in the Asian Indian immigrant community in the U.S. Sex Roles, 38(11/12), 953-974.

DeBiaggi, S. (2003). Famílias brasileiras em um novo contexto cultural. In A. Martes \& S. Fleischer (Orgs.), Fronteiras Cruzadas: etnicidade, gênero e redes sociais (pp. 175-197). São Paulo: Paz e Terra.

Dion, K. \& Dion, K. (2001). Gender and cultural adaptation in immigrant families. Journal of Social Issues, 51(3), 511-521.

Donato, K. (1992). Understanding U.S. immigration: Why some countries send women and others send men. In D. Gabaccia (Ed.), Seeking common ground: Multidisciplinary studies of immigrant women in the United States (pp.159-184). Westport, CT: Praeger.

Espin, O. (1987). Psychological impact of migration on Latinas: Implications for psychotherapeutic practice. Psychology of Women Quaterly, 489-503.

Feldman-Bianco, B. \& Huse, D. (1995). Entre a saudade da terra e a América: mulheres imigrantes. Estudos Feministas, 3(1), 96-121.

Fleischer, S. (2002). Passando a América a limpo: o trabalho de housecleaners brasileiras em Boston, Massachussets. São Paulo: Annablume.

Gowan, M. \& Trevi, M. (1998). An examination of gender differences in Mexican-American attitudes toward family and career roles. Sex Roles, 38, 1079-1093.

Hall, S. (2000). A identidade cultural na pós-modernidade (4ª ed., T. Tadeu \& G. L. Louro, Trad.). Rio de Janeiro: DP\&A Editora.

Kosminsky, E. (2004). Questões de gênero em estudos comparativos de imigração: mulheres judias em São Paulo e em Nova York. Cadernos Pagu, 23, 279-328.

Kranau, E., Green, V., \& Valencia-Weber, G. (1982). Acculturation and the Hispanic woman: Attitudes toward women, sex-role attribution, sex-role behavior, and demographics. Hispanic Journal of Behavioral Sciences, 4(1), 21-40.

Leite, M. L. M. (1997). Mulheres viajantes do século XIX. In M. Schpun (Org.), Gênero sem fronteiras: oito olhares sobre mulheres e relações de gênero (pp. 25-42). Florianópolis: Editora Mulheres.

Lewin, F. A. (2001). Identity crisis and integration: The divergent attitudes of Iranian immigrant men and women towards integration into Swedish society. International Migration, 39(3), 121-135.

Lim, I. (1997). Korean immigrant women's challenge to gender inequality at home: The interplay of economic resources, gender, and family. Gender \& Society, 11(1), 31-51. 
Louro, G. (1995). Gênero, história e educação: construção e desconstrução. Educação \& Realidade, 20(2), 101-132.

Louro, G. (1997). Gênero, sexualidade e educação: uma perspectiva pós-estruturalista ( $2^{\mathrm{a}}$ ed.). Petrópolis, RJ: Vozes. Martes, A. (1998). Brasileños en Massachussetts. Estudios Migratorios Latinoamericanos, 13(39), 257-287.

Pereira, V. L. (2004). Gênero: dilemas de um conceito. In M. Strey, S. Cabeda, \& D. Prehn (Orgs.), Gênero e cultura: questões contemporâneas (pp. 173-198). Porto Alegre: Edipucrs.

Pyke, K. \& Johnson, D. (2003). Asian American women and racialized feminities: "Doing" gender across cultural worlds. Gender \& Society, 17(1), 39-53.

Scott, J. (1995). Gênero: uma categoria útil de análise histórica. Educação \& Realidade, 20(2), 71-99.

Simon, R. (1992). Sociology and immigrant women. In D. Gabaccia (Ed.), Seeking common ground: Multidisciplinary studies of immigrant women in the United States (pp. 23-40). Westport, CT: Praeger.

Soto, E. \& Shaver, P. (1982). Sex-role traditionalism, assertiveness, and symptoms of Puerto Rican women living in the United States. Hispanic Journal of Behavioral Sciences, 4(1), 1-19.

Souza, I. (2007). A integração de imigrantes brasileiras em Roma: conquistas e dificuldades. Imaginário, 13(14), 399-415.

Strey, M. (2001). Violência e gênero: um casamento que tem tudo para dar certo. In P. Grossi \& G. Werba (Orgs.), Violências e gênero: coisas que a gente não gostaria de saber (pp. 47-69). Porto Alegre: Edipucrs.

Valentine, S. \& Mosley, G. (2000). Acculturation and sex-role attitudes among Mexican Americans: A longitudinal analysis. Hispanic Journal of Behavioral Sciences, 22(1), 104-113.

Vicente, A. (1999). As mulheres nos mundos de hoje. In H. Holanda \& M. Capelato (Orgs.), Relações de gênero e diversidades culturais nas Américas. Rio de Janeiro: Expressão e Cultura; São Paulo: Edusp.

Weinberg, S. (1992). The treatment of women in immigration history: A call for change. In D. Gabaccia (Ed.), Seeking common ground: Multidisciplinary studies of immigrant women in the United States (pp. 3-22). Westport, CT: Praeger.

Woodward, K. (2001). Identidade e diferença: uma introdução teórica e conceitual. In T. Sillva (Org.), Identidade e diferença: a perspectiva dos estudos culturais. Petrópolis, RJ: Vozes.
Roberta de Alencar-Rodrigues é Psicóloga graduada pela Pontifícia Universidade Católica do Rio Grande do Sul (PUCRS), Mestre em Psicologia Social e da Personalidade pela PUCRS, através da Bolsa Capes. Doutoranda em Psicologia Social pela Universidade Autônoma de Barcelona (UAB), com apoio do Programa Alban, Programa de Bolsas de Alto-Nível da União Europeia para a América Latina. Email: Roberta.Alencar@campus.uab.cat

Marlene Neves Strey é Professora Titular do Departamento de Psicologia, na PUCRS, Coordenadora do grupo Relações de Gênero. Pós-Doutorado em Psicologia na Universidade de Barcelona (UB). Endereço para correspondência: Programa de Pós-Graduação em

Psicologia. Avenida Ipiranga, 6681 - Prédio 11 - $9^{\circ}$ andar, sala 941. Porto Alegre/RS. CEP: 90619-900. Email: streymn@pucrs.br

Leonor Cantera Espinosa é Professora de Psicologia Social da Universidade Autônoma de Barcelona (UAB), Diretora do Mestrado Interdisciplinar em Estudo e Intervenção sobre Violência Doméstica. Endereço para correspondência: Departamento de Psicologia Social, Faculdade de Psicologia, Edificio B. Campus de la UAB, 08193 Belaterra (Cerdanyola del Vallès), Barcelona, España.

\section{Marcas do gênero nas migrações internacionais das mulheres}

Roberta de Alencar-Rodrigues, Marlene Neves Strey e Leonor Cantera Espinosa

Recebido em: 07/07/2008

Revisão em: 29/09/2009

Aceite final em: 03/10/2009 